\title{
Effects of Additional Milk Replacer Feeding on Calf Health, Growth, and Selected Blood Metabolites in Calves
}

\author{
J. D. Quigley, ${ }^{\star 1,2}$ T. A. Wolfe, ${ }^{\star 3}$ and T. H. Elsasser† \\ *APC, Inc., Ankeny, IA 50021 \\ †Growth Biology Laboratory, USDA-ARS, Beltsville, MD 20705
}

\begin{abstract}
The objective of the experiment was to evaluate effects of increased milk replacer feeding on growth, intake, feed efficiency, and health parameters in stressed calves. Holstein bull calves $(\mathrm{n}=120$; approximately 3 to $8 \mathrm{~d}$ of age) were purchased from sale barns and dairy farms and housed in fiberglass hutches. In addition, wood shavings contaminated with coronavirus were mixed with clean shavings and added to each hutch before the start of the experiment. Calves were fed either a fixed amount $(454 \mathrm{~g} / \mathrm{d})$ of a $20 \%$ crude protein (CP), $20 \%$ fat milk replacer to weaning at $28 \mathrm{~d}$ or a variable amount $(454,681,908$, and $454 \mathrm{~g} / \mathrm{d}$ on $\mathrm{d} 0$ to 7,8 to 14,15 to 31 , and 32 to 41 , respectively) of a milk replacer containing $28 \% \mathrm{CP}$ and $17 \%$ fat without or with added dietary supplement containing bovine serum. Calves were also fed commercial calf starter and water ad libitum. Plasma IgG concentration in most calves on arrival at the facility was $<10 \mathrm{~g} / \mathrm{L}$. Intake, change in body weight, feed efficiency, morbidity and mortality, and selected plasma metabolites were determined. Body weight at $28 \mathrm{~d}, 56 \mathrm{~d}$, daily body weight gain, intake of milk replacer, fecal scores, days with diarrhea, and days treated with antibiotics were increased with feeding variable amount of milk replacer over the 56-d study. Starter intake from d 1 to 56 was reduced from 919 to $717 \mathrm{~g} / \mathrm{d}$ in calves fed fixed and variable amounts of milk replacer, respectively. Morbidity, measured as the number of days that calves had diarrhea, was increased by $53 \%$ when a variable amount of milk replacer was fed. Calves fed variable milk replacer were treated with antibiotics for $3.1 \mathrm{~d}$ compared with $1.9 \mathrm{~d}$ for calves fed $454 \mathrm{~g}$ of milk replacer/ d. Concentrations of plasma glucose, urea $\mathrm{N}$, and insulin-like growth factor-I were increased when calves
\end{abstract}

Received May 18, 2005.

Accepted September 8, 2005.

${ }^{1}$ Corresponding author: jquigley@diamondv.com

${ }^{2}$ Current address: Diamond V Mills, Inc., Cedar Rapids, Iowa 52407.

${ }^{3}$ Current address: College of Veterinary Medicine, Iowa State University, Ames 50011. were fed variable amount of milk replacer. Dietary supplement containing bovine serum had no effect on any parameter measured. There was no effect of milk replacer feeding on concentrations of nonesterified fatty acids, total protein, or growth hormone concentrations. Plasma tumor necrosis factor- $\alpha$ was highest in calves with the highest plasma IgG concentrations on the day of arrival and might be related to the calf's ability to identify pathogens in the environment. Under conditions of this study, calves fed variable amount of milk replacer and exposed to immunological challenge before weaning had greater BW gain, but also increased incidence of diarrhea that required added veterinary treatments.

Key words: calf, milk replacer, growth, health

\section{INTRODUCTION}

Efficient growth of young dairy calves is important to profitability of the dairy enterprise. Before weaning, intake of nutrients from liquid feeds is usually limited to stimulate early dry feed intake and allow development of ruminal function and early weaning (Bush and Nicholson, 1986). Effects of feeding additional liquid milk or milk replacer to calves have been evaluated. Generally, increased intake of nutrients consumed in liquid causes less starter and forage intake (Jasper and Weary, 2002), increased BW gain (Brown et al., 2005), and greater deposition of fat and protein (Diaz et al., 2001).

Neonatal calves are susceptible to many environmental pathogens; consequently, morbidity and mortality can be high (NAHMS, 1993). Pathogenic infections can initiate an immune response, with concomitant production of cytokines such as tumor necrosis factor- $\alpha$ (TNF$\alpha$ ), IL-6, and IL-1 $\beta$ (Elsasser et al., 1998; Escobar et al., 2002), although increased concentration of peripheral cytokines has not always been reported (Balaji et al., 2002). Proinflammatory cytokines may reduce intake (Johnson, 1998; Jenkins et al., 2004) and growth rate and reduce circulating concentrations of IGF-I in pigs (Turner et al., 2002; Jenkins et al., 2004) and cattle (Elsasser et al., 1995). 
Table 1. Ingredient composition of experimental milk replacers

\begin{tabular}{lrr}
\hline & \multicolumn{2}{c}{ Milk replacer $^{1}$} \\
\cline { 2 - 3 } Ingredient, \% as fed & CON & VAR \\
\hline Whey protein concentrate, 34\% & 49.27 & 63.49 \\
Dry fat, 7/60 & 33.45 & 25.00 \\
Dried whey & 12.23 & 0.00 \\
Vitamin/mineral/AA premix ${ }^{2}$ & 2.50 & 2.50 \\
Salt & 0.36 & 0.31 \\
Whey protein concentrate, 75\% & 0.00 & 6.40 \\
Dicalcium phosphate, 18.5\% & 2.19 & 2.30 \\
\hline
\end{tabular}

${ }^{1}$ Ingredients on an air-dry basis. $\mathrm{CON}=$ milk replacer fed at 454 $\mathrm{g} / \mathrm{d}$; VAR $=$ milk replacer fed at $454,681,908$, and $454 \mathrm{~g} / \mathrm{d}$ on $\mathrm{d} 0$ to 7,8 to 14,15 to 31 , and 32 to 41 , respectively.

${ }^{2}$ Vitamin and mineral premix provided per kilogram: lysine, $62 \mathrm{~g}$; methionine, $52 \mathrm{~g}$; choline chloride, $19.8 \mathrm{~g}$; vitamin A, 4,408 kIU; vitamin D3, $882 \mathrm{kIU}$; vitamin E, $13.2 \mathrm{kIU}$; vitamin K, $264 \mathrm{mg}$; vitamin C, $4.4 \mathrm{~g}$; thiamin, $176 \mathrm{mg}$; riboflavin, $441 \mathrm{mg}$; pantothenic acid, 1437 $\mathrm{mg}$; niacin, $1322 \mathrm{mg}$; pyridoxine, $441 \mathrm{mg}$; biotin, $4.4 \mathrm{mg}$; folic acid, $33 \mathrm{mg}$; vitamin B12, $3.5 \mathrm{mg}$; magnesium, $12.8 \mathrm{~g}$; manganese, 2,204 mg; iron, 4,281 mg; copper, 970 mg; cobalt, $44.1 \mathrm{mg}$; zinc, 3.8 g; iodine, $176 \mathrm{mg}$; selenium, $11.9 \mathrm{mg}$.

Because neonatal calves are often exposed to significant environmental and immunological stressors, provision of additional nutrients may exacerbate health problems and cause anorexia. Johnson (1998) suggested that anorexia associated with immunological challenge may be an adaptive response and force-feeding of anorexic animals may increase mortality. Therefore, the objective of this study was to determine effects of increased liquid feeding in stressed calves on growth, intake, efficiency, and health parameters.

\section{MATERIALS AND METHODS}

Holstein bull calves $(n=120)$ were purchased from local area dairies or sale barns and were shipped to the APC Calf Research Unit in Ames, IA. Calves were received in 2 groups of 60 calves on May 19 and May 26,2002 , with their use on the study initiated the next day. Calves were approximately 3 to $8 \mathrm{~d}$ of age; however, age of calves on arrival was not determined.

On arrival, calves were unloaded from the truck, moved to individual fiberglass hutches, and assigned randomly to receive 1 of 3 experimental treatments $(\mathrm{n}=$ 40 per treatment). Treatments were nonmedicated calf milk replacer (CMR; Table 1) formulated to contain $20 \% \mathrm{CP}$ and $20 \%$ fat (CON) offered at $454 \mathrm{~g} / \mathrm{d}$ of CMR divided into 2 daily feedings; a CMR containing $28 \%$ $\mathrm{CP}$ and $16 \%$ fat offered at $454,681,908$, and $454 \mathrm{~g} / \mathrm{d}$ during $d 0$ to 7,8 to 14,15 to 31 , and 32 to 41 , respectively (VAR); or VAR with the addition of Gammulin (APC, Inc., Ankeny, IA) at a rate of 60,45 , and $30 \mathrm{~g} / \mathrm{d}$ during d 1 to 5,6 to 10 , and 11 to 15 (GAM) mixed into the CMR immediately before each feeding.
Calves were fed CMR twice daily at approximately 0700 and $1600 \mathrm{~h}$ using nipple bottles. The CMR were mixed in hot water (approximately $50^{\circ} \mathrm{C}$ ) to disperse fat. Cool water was then added to bring temperature to approximately $39^{\circ} \mathrm{C}$ and appropriate $\mathrm{DM}$ prior to feeding. Amount of liquid used was $3.8 \mathrm{~L} / \mathrm{d}(\mathrm{CON})$ and 3.8, 5.6, 7.2, and 3.8 L/d (VAR and GAM) during the 4 periods. Calves fed CON, VAR, and GAM treatments were weaned on d 28, 42, and 42, respectively. Any CMR refused by calves was weighed and then administered using an esophageal feeder.

Commercial textured calf starter (CS; Cargill Herd Builder, Cargill, Inc., Minnetonka, MN) was offered once daily for ad libitum consumption, and feed refusals were measured daily. Water was offered once daily for ad libitum consumption. Refusals of water were measured, and water intake was assumed to equal water offered minus water refused. No hay was fed. Hutches were bedded with clean shavings throughout the study. A small amount (approximately $2 \mathrm{~kg}$ ) of bedding from a previous study was added to each hutch. The previous study included a coronavirus challenge for all calves; therefore, we anticipated that all calves in this study were exposed to coronavirus during the study.

Jugular blood was collected from each calf on arrival into evacuated tubes containing EDTA and a subsample was collected for measurement of hematocrit by microhematocrit centrifuge. Tubes were then centrifuged and plasma was separated and tested for total protein using a refractometer; the remaining plasma was frozen $\left(-20^{\circ} \mathrm{C}\right)$ until analyzed for IgG by turbidimetric immunoassay (Etzel et al., 1997). Calves were blocked by Ig status, based on plasma IgG concentration on arrival (adequate $=$ plasma IgG $>10.0 \mathrm{~g} / \mathrm{L} ;$ marginal $=5.0$ to $10.0 \mathrm{~g} / \mathrm{L}$; and deficient $=<5.0 \mathrm{~g} / \mathrm{L}$ ).

Samples of CMR and CS were collected weekly and stored $\left(-20^{\circ} \mathrm{C}\right)$ prior to analysis for $\mathrm{DM}, \mathrm{CP}$, ether extract (Mojonnier assay), ADF (CS only), ash, and $\mathrm{Ca}$, $\mathrm{P}, \mathrm{K}$, and $\mathrm{Mg}$ (AOAC, 1990). Calves were weighed once weekly starting on d 0 . Fecal consistency was qualitatively scored once daily using a scale of $1=$ normal fecal consistency (solid appearance), $2=$ slightly liquid consistency, 3 = moderately liquid consistency, and $4=$ primarily liquid consistency (severe scours). When fecal material was unavailable for scoring, calves were assigned a missing value. A scour day was defined when calves had a fecal score $>2$. Rectal temperatures were determined on calves with fecal score $>2$. Treatment with antibiotics was initiated when an animal had a rectal temperature $>39.4^{\circ} \mathrm{C}$. Electrolyte therapy was initiated when calves had fecal score $>2$, or were visibly dehydrated and continued until signs of disease abated. Daily mean high and low ambient temperature, relative 
Table 2. Chemical composition of experimental diets ${ }^{1}$

\begin{tabular}{|c|c|c|c|c|}
\hline \multirow[b]{2}{*}{ Nutrient $^{2}$} & \multicolumn{2}{|c|}{ Milk replacer } & \multirow[b]{2}{*}{ GAM } & \multirow{2}{*}{$\begin{array}{l}\text { Calf } \\
\text { starte }\end{array}$} \\
\hline & $\mathrm{CON}$ & VAR & & \\
\hline $\mathrm{DM}, \%$ & 96.72 & 96.61 & 94.56 & 87.47 \\
\hline $\mathrm{CP}, \%$ & 20.58 & 28.02 & 64.28 & 21.61 \\
\hline Fat, \% & 20.92 & 16.72 & 4.16 & 4.62 \\
\hline Ash, \% & 7.64 & 6.10 & 8.33 & 5.34 \\
\hline Calcium, \% & 1.56 & 1.26 & 0.73 & 0.83 \\
\hline Phosphorus, \% & 0.83 & 0.80 & 0.44 & 0.75 \\
\hline Potassium, \% & 0.75 & 0.63 & 0.26 & 0.82 \\
\hline Magnesium, \% & 0.14 & 0.13 & 0.30 & 0.23 \\
\hline $\mathrm{ADF}, \%$ & - & - & - & 4.82 \\
\hline Lactose $^{3}$ & 50.86 & 49.16 & - & - \\
\hline $\mathrm{ME}, \mathrm{Mcal} / \mathrm{kg}^{4}$ & 4.755 & 4.728 & 3.289 & 3.712 \\
\hline
\end{tabular}

${ }^{1} \mathrm{CON}=$ Milk replacer fed at $454 \mathrm{~g} / \mathrm{d}$; VAR $=$ milk replacer fed at $454,681,908$, and $454 \mathrm{~g} / \mathrm{d}$ on d 0 to 7,8 to 14,15 to 31 , and 32 to 41 , respectively; GAM = dietary supplement containing bovine serum.

${ }^{2}$ Data are on an air-dry basis.

${ }^{3}$ Calculated as 100 - protein - fat - ash.

${ }^{4}$ Metabolizable energy, calculated from NRC $(2001)$ as: $(0.057 \times \mathrm{CP}$ $\%+0.092 \times$ fat $\%+0.0395 \times$ lactose $\%) \times 0.97 \times 0.96$ for calf milk replacer $(\mathrm{CMR})$ and $(0.057 \times \mathrm{CP} \%+0.094 \times$ fat $\%+0.0415 \times$ carbohydrate \% $\times 0.82$ to calculate $\mathrm{DE} . \mathrm{ME}=(1.01 \times \mathrm{DE}-0.45)+[0.0046$ $\times($ fat $\%-3)]$ for starter and additive. Carbohydrate $=100-$ protein - fat - ash.

humidity, and solar radiation were obtained from ISU Campbell Network, Iowa State University (Ames).

On d 7, 14, 28, 42, and 56, blood samples were collected by jugular venipuncture and plasma collected and stored $\left(-20^{\circ} \mathrm{C}\right)$. Plasma was analyzed for concentrations of TNF- $\alpha$, IGF-I, and growth hormone (GH) as described in Elsasser et al. (1998) and total protein, plasma urea N (PUN), glucose, and NEFA using colorimetric kits (Roche Diagnostic Systems, Inc., Branchburg, NJ) and a clinical analyzer (Cobas Mira, Roche Analytical Instruments, Montclaire, NJ).

Data were analyzed by ANOVA using SAS (SAS Institute, 1990). Health and growth data were summarized over the 56-d study and analyzed using a randomized complete block experimental design. Daily intake of CS, CMR, water, and weekly BW and feed efficiency were analyzed as repeated measures ANOVA using the Mixed procedure of SAS. Covariance structures were modeled as described in Littell et al. (1998). Orthogonal contrasts were used to evaluate differences due to level of CMR feeding (CON vs. VAR and GAM) and effect of supplement (VAR vs. GAM). Mortality and proportion of calves that required veterinary treatments or developed diarrhea were analyzed by $\chi^{2}$ analysis using the Mixed procedure of SAS. Significance was declared at $P<0.05$ unless otherwise noted.

\section{RESULTS AND DISCUSSION}

Chemical composition of experimental diets is in Table 2. Experimental CMR were similar to formulated values and amount of $\mathrm{CP}$ and fat varied between products fed. Gammulin and calf starter had higher CP than label values.

Environmental temperatures during the trial were generally within the thermoneutral range for young calves, except for the first week of the study, when mean daily low temperatures were less than $10^{\circ} \mathrm{C}$. Mean daily high temperatures were $>20^{\circ} \mathrm{C}$, except on $\mathrm{d} 1,2,5,6$, and 15.

Four calves died within $3 \mathrm{~d}$ of arrival at the research facility ( $\mathrm{n}=3$ in CON, $\mathrm{n}=1$ in VAR). All of these animals showed clinical signs of disease within $1 \mathrm{~d}$ of arrival; therefore, all data from these calves were deleted from the data set before analysis. Data from other calves that died during the study were included until time of death.

Overall mortality of calves during the study was 17 calves $(12.3 \%$, excluding calves that died within $3 \mathrm{~d}$ of arrival). There was no difference among treatments $(P=$ 0.21 ) over the entire 56-d study (Table 3 ); however, preweaning mortality tended $(P<0.10)$ to be greater in calves fed additional CMR (VAR and GAM) compared with CON. Addition of the dietary supplement had no effect on preweaning or total mortality. Fourteen calves fed additional CMR died at an average of $12.6 \mathrm{~d}$; and 3 calves on CON treatment died at an average of 14.0 d. Because calves were of varying ages and backgrounds prior to arrival at the research facility, it is possible that previous pathogenic exposure was responsible for observed mortality, particularly in the first week. Therefore, it is difficult to determine precisely the contribution to mortality from previous pathogen exposure and that caused by imposition of dietary treatments. We concluded that after $3 \mathrm{~d}$ of the study, it was likely that dietary treatments (particularly intake of energy and protein from CMR) would affect clinical outcome. Of calves fed additional CMR, 1, 10, and 2 calves died during wh 1,2 , and 4 , respectively. Of calves fed CON, 2 and 1 calves died during wk 1 and 5, respectively. The second week of the study was the week of highest fecal scores and greatest number of veterinary treatments for both groups of calves. The increase in amount of CMR offered to calves fed additional CMR from 454 to $681 \mathrm{~g} / \mathrm{d}$ on d 8 constituted a $50 \%$ increase in feeding rate at the time when calves were dealing with enteric challenges. It is possible that the abrupt change in feeding rate may have contributed to increased morbidity and mortality; however, further research is needed to confirm this observation.

Necropsies were conducted on most calves that died (Veterinary Diagnostic Laboratory, Iowa State University). Clinical signs and necropsy results were consistent with enteric infections and Salmonella, Cryptosporidium parvum, coronavirus, and Escherichia coli 
Table 3. Least squares means of animal performance in calves ${ }^{1}$ fed experimental diets

\begin{tabular}{|c|c|c|c|c|c|c|c|c|}
\hline & \multicolumn{6}{|c|}{ Treatments $^{2}$} & \multicolumn{2}{|c|}{ Contrasts $^{3}$} \\
\hline & $\mathrm{CON}$ & SEM & VAR & SEM & GAM & SEM & 1 & 2 \\
\hline \multicolumn{9}{|l|}{ Number of calves } \\
\hline Begin & 37 & - & 39 & - & 40 & - & - & - \\
\hline End & 34 & - & 30 & - & 35 & - & - & - \\
\hline Mortality, \% & 8.6 & 6.0 & 22.3 & 5.7 & 12.6 & 5.7 & NS & NS \\
\hline Mortality, d & 14.0 & - & 13.0 & - & 12.0 & - & - & - \\
\hline $\operatorname{IgG}, \mathrm{g} / \mathrm{L}$ & 8.3 & 0.5 & 9.0 & 0.5 & 8.4 & 0.5 & NS & NS \\
\hline Hematocrit, \% & 34.0 & 1.1 & 34.2 & 1.0 & 35.1 & 1.0 & NS & NS \\
\hline Total protein, g/L & 58.1 & 0.9 & 57.6 & 0.9 & 57.3 & 0.9 & NS & NS \\
\hline Fecal scores & 1.44 & 0.05 & 1.60 & 0.05 & 1.56 & 0.05 & 0.02 & NS \\
\hline Fever, $\%$ of calves & 26.6 & 7.6 & 27.5 & 7.2 & 33.5 & 7.2 & NS & NS \\
\hline Fever, d & 0.4 & 0.2 & 0.5 & 0.2 & 0.7 & 0.2 & NS & NS \\
\hline Scours, $\%$ of calves & 72.8 & 6.8 & 84.8 & 6.4 & 82.9 & 6.4 & NS & NS \\
\hline Scours, d & 1.7 & 0.3 & 2.7 & 0.3 & 2.5 & 0.3 & 0.03 & NS \\
\hline Electrolytes, $\%$ of calves & 27.2 & 8.0 & 32.9 & 7.5 & 48.8 & 7.5 & NS & NS \\
\hline Electrolytes, d & 0.3 & 0.1 & 0.5 & 0.1 & 0.7 & 0.1 & 0.11 & NS \\
\hline Antibiotics, $\%$ of calves & 48.7 & 8.0 & 61.4 & 7.5 & 72.5 & 7.5 & 0.05 & NS \\
\hline Antibiotics, $\mathrm{d}$ & 1.9 & 0.5 & 3.0 & 0.5 & 3.2 & 0.5 & 0.05 & NS \\
\hline
\end{tabular}

\footnotetext{
${ }^{1}$ Data exclude calves that died within $3 \mathrm{~d}$ of arrival.

${ }^{2}$ Treatments: $\mathrm{CON}=$ calves fed $454 \mathrm{~g} / \mathrm{d}$ of calf milk replacer $(\mathrm{CMR})$ to $28 \mathrm{~d}$; VAR $=$ calves fed 454,681 , 908, and $454 \mathrm{~g} / \mathrm{d}$ of CMR on d 0 to 7,8 to 14,15 to 31 , and 32 to $41 \mathrm{~d}$, respectively; GAM = calves fed CMR as VAR with dietary supplement added at 60,45 , and $30 \mathrm{~g} / \mathrm{d}$ on d 1 to 5,6 to 10 and 11 to 15 , respectively.

${ }^{3}$ Contrasts: $1=\mathrm{CON}$ vs. $(\mathrm{VAR}+\mathrm{GAM}) / 2 ; 2=\mathrm{VAR}$ vs. GAM.
}

were identified as sources of mortality. Pneumonia was also diagnosed as a cause of mortality in 2 calves. Plasma IgG, total protein, and hematocrit on arrival at the facility did not differ by treatment. Seventy-one calves $(63 \%)$ had plasma IgG concentrations $<10 \mathrm{~g} / \mathrm{L}$, indicating failure of passive transfer; 32 calves had $<6 \mathrm{~g}$ of IgG/L, indicating complete failure of colostral intake.

Indices of animal health (Table 3) suggested that additional CMR feeding resulted in greater health problems under the conditions of this study. Fecal scores, days with scours, proportion of calves treated with antibiotics, and number of days calves were treated with antibiotics were greater when additional CMR was fed. Moreover, the number of days that calves were treated with electrolytes tended $(P<0.11)$ to be greater when calves were fed additional CMR. That antibiotic therapy was greater in calves fed additional CMR was of interest because therapy was initiated only when calves had a rectal temperature $>39.4^{\circ} \mathrm{C}$. Rectal temperatures were measured when calves had clinical signs of disease (anorexia, diarrhea, etc.). It is possible that calves on CON treatment also had elevated rectal temperatures but fewer clinical signs of disease (e.g., diarrhea) than calves fed additional CMR. However, there was no difference in the percentage of calves that exhibited one or more days with fever or number of days that calves had fever (Table 3). Feeding additional CMR may increase fecal scores in preweaned calves, particularly within the first 2 wk (Diaz et al., 2001; Brown et al., 2005), and increased days treated for illness (Ballard et al., 2004). Conversely, Jasper and Weary (2002) reported no significant effect of CMR feeding method on fecal scores when whole milk was fed to calves. Foote et al. (2004) reported little effect of feeding $1.14 \mathrm{~kg} / \mathrm{d}$ of CMR (28\% CP, $20 \%$ fat) compared with calves fed $0.57 \mathrm{~kg} / \mathrm{d}$ of CMR (22\% CP, $20 \%$ fat) on antigen-specific responses of vaccinated dairy calves, suggesting that amount of CMR feeding may have limited influence on immune response.

Administration of GAM did not affect any parameter measured in the study. Previous research (Quigley et al., 2002) indicated that administration of GAM, which contained bovine serum as a source of IgG, reduced the number of days that calves scoured and reduced the use of electrolytes and antibiotics. Oral administration of Ig to calves after cessation of macromolecular transport can reduce the incidence or severity of enteric infections in calves (Nollet et al., 1999; Quigley and Drew, 2000; Hunt et al., 2002). Conditions in the current study due to the types of pathogens and specificity of IgG used or the high level of exposure due to introduction of coronavirus-infected bedding during the study might have overwhelmed any potential benefit provided by feeding GAM.

Least squares means of $\mathrm{BW}$ on d 0 were similar among treatments and mean initial BW was $45.4 \mathrm{~kg}$. On d 28 and 56, BW was higher in calves fed additional CMR (Table 4). Least squares means of weekly BW (Figure 1) show clearly the effect of feeding additional nutrients. By 2 wk of age, calves fed VAR and GAM 
Table 4. Least squares means of BW, BW gain, and intake in calves ${ }^{1}$ fed experimental diets

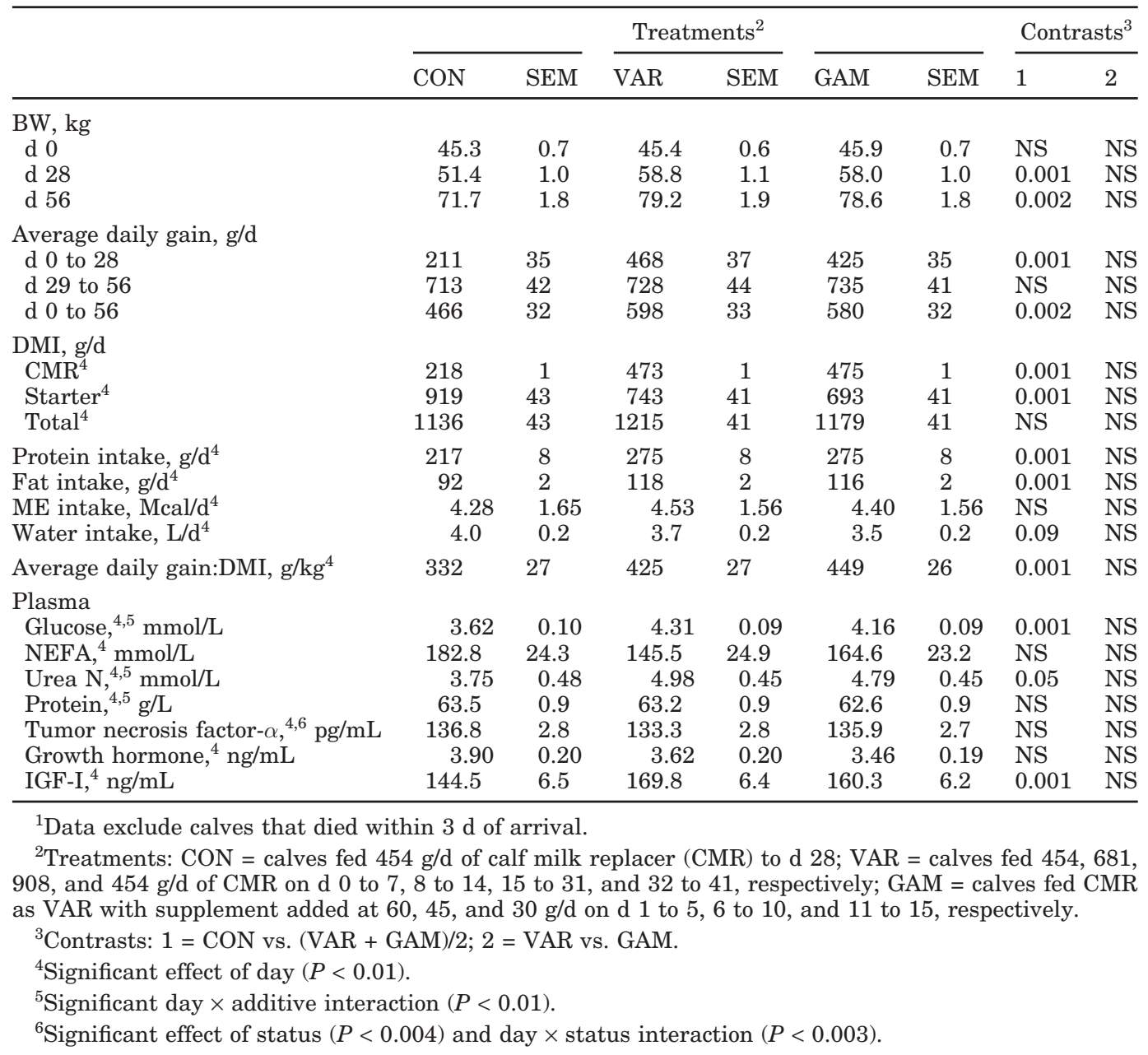

were heavier. Following weaning at $28 \mathrm{~d}(\mathrm{CON})$ and 42 $\mathrm{d}$ (VAR and GAM), there was little change in BW curves (Figure 1), suggesting that calves were able to obtain nutrients from CS at either age.

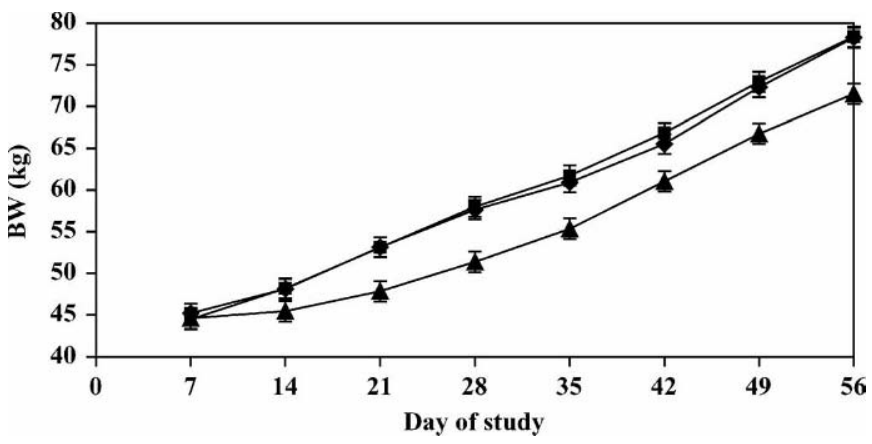

Figure 1. Weekly BW of calves fed calf milk replacer (CMR) at $454 \mathrm{~g} / \mathrm{d}(\mathbf{\Delta})$ to $28 \mathrm{~d}$ or 454 to $908 \mathrm{~g} / \mathrm{d}$ of CMR to $42 \mathrm{~d}$ without (ם) or with added dietary supplement $(\diamond)$.
Increased BW in response to added CMR feeding is similar to data of Brown et al. (2005) who reported that calves fed CMR (30\% CP, $16 \%$ fat) at $2 \%$ of BW weighed $12 \mathrm{~kg}$ more at 8 wk of age than calves fed a CMR containing $21 \% \mathrm{CP}$ and $21 \%$ fat and fed at $1 \%$ of BW.

Similar to BW, gain in BW was greater in calves fed VAR from d 0 to 29 and 0 to 56 (Table 4). However, gain in BW did not vary during the last $28 \mathrm{~d}$ of the study, when calves fed CON were weaned and calves fed additional CMR received decreasing amount of CMR.

Efficiency of feed use was $26 \%$ greater in calves fed additional CMR (Table 4). Feed efficiency in this study was less than that reported by Brown et al. (2005), who reported 439 and $550 \mathrm{~g}$ of BW gain/kg of DM intake in calves fed CMR at 1 and $2 \%$ of BW, respectively, from 2 to $8 \mathrm{wk}$ of age. However, those authors removed from their data set calves that died during the study (18 of 74 calves), which would skew the data upward, because calves that die are usually least efficient. Our data included calves that died except those that died within 


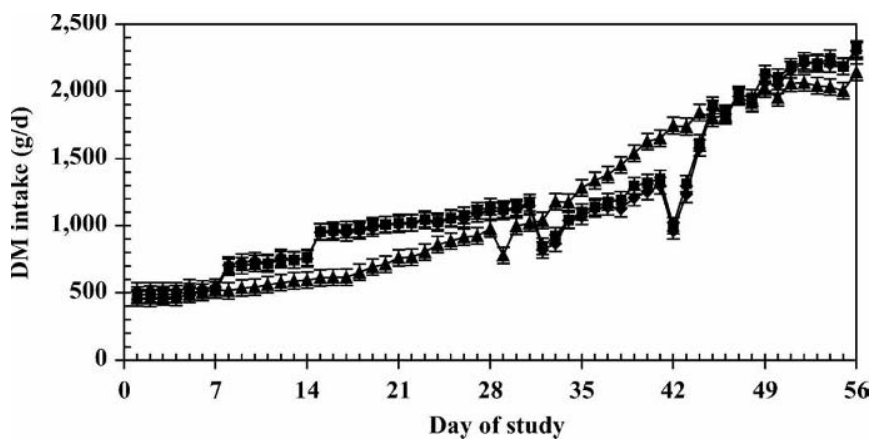

Figure 2. Total DM intake of calves fed calf milk replacer (CMR) at $454 \mathrm{~g} / \mathrm{d}(\mathbf{\Lambda})$ to $28 \mathrm{~d}$ or 454 to $908 \mathrm{~g} / \mathrm{d}$ of CMR to $42 \mathrm{~d}$ without (ם) or with added dietary supplement $(\bullet)$.

the first $3 \mathrm{~d}$ of the study. Further, calves in the study of Brown et al. (2005) were assigned to treatment only after a 7-d adaptation period, which is usually when calves are least efficient. In our study, calves lost approximately $300 \mathrm{~g}$ of $\mathrm{BW} / \mathrm{d}$ in the first $7 \mathrm{~d}$ after arrival and therefore had negative gain to feed ratios.

Intake of CMR and CS were affected by type of CMR fed and a day $\times$ treatment interaction (Table 4). Overall CMR intake was more than 2-fold greater when calves were offered additional CMR. However, intake of CS was $22 \%$ lower. Although intake of CMR and CS differed between treatments, overall intake of DM and $\mathrm{ME}$ were similar among treatments. Intake of CMR and consumption of $\mathrm{CP}$ and fat were greater when calves were fed additional CMR.

Least squares means of total DM and CS intake were affected by a day $\times$ treatment interaction $(P<0.0001)$. Total DM (Figure 2) and CS (Figure 3 ) intakes increased in a curvilinear fashion to $48 \mathrm{~d}$ in calves fed CON; thereafter, DM intake was essentially constant to 56 d. Intake of total DM in calves fed VAR or GAM was

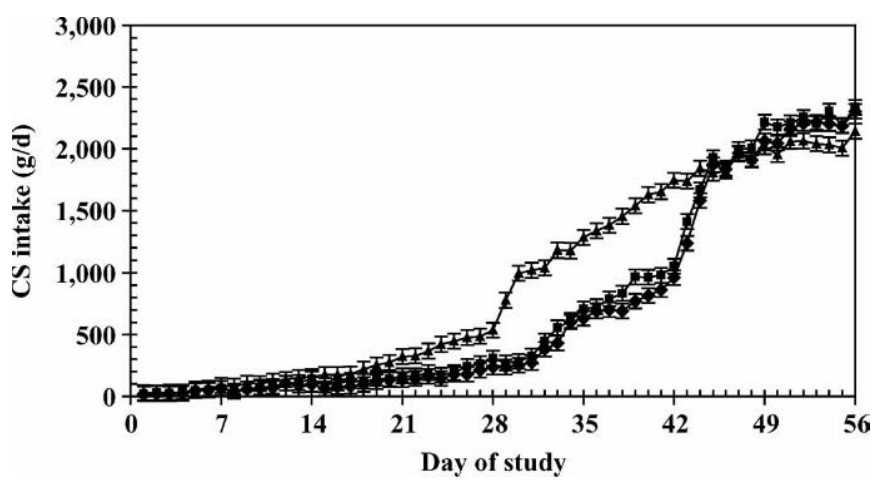

Figure 3. Calf starter (CS) intake of calves fed calf milk replacer $(\mathrm{CMR})$ at $454 \mathrm{~g} / \mathrm{d}(\mathbf{\Delta})$ to $28 \mathrm{~d}$ or 454 to $908 \mathrm{~g} / \mathrm{d}$ of CMR to $42 \mathrm{~d}$ without $(\square)$ or with added dietary supplement $(\bullet)$.

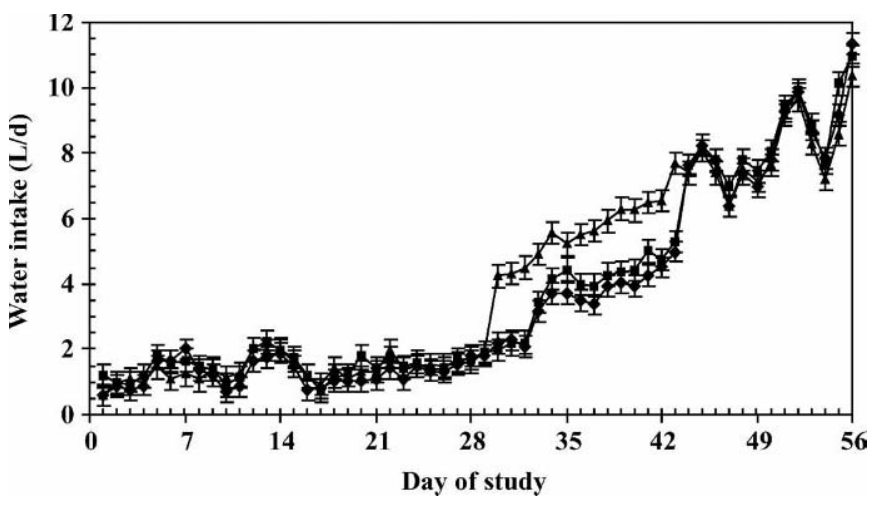

Figure 4. Calf water intake of calves fed calf milk replacer (CMR) at $454 \mathrm{~g} / \mathrm{d}(\boldsymbol{\Delta})$ to $28 \mathrm{~d}$ or 454 to $908 \mathrm{~g} / \mathrm{d}$ of CMR to $42 \mathrm{~d}$ without (ם) or with added dietary supplement $(\bullet)$.

high until amount of CMR offered was reduced on d 32. However, CS intake was low in calves fed additional CMR until d 32. Thereafter, total DM intake increased linearly to weaning on $\mathrm{d} 42$. Weaning caused a reduction in total DM intake for $3 \mathrm{~d}$; thereafter, the rate of increase in DM intake was similar to that from d 31 .

Intake of $\mathrm{ME}$ for the entire experiment did not vary by treatment (Table 4), although a day $\times$ treatment interaction was significant (data not shown). Intake of both CP and fat were greater in calves fed VAR and GAM compared with CON (data not shown), due to greater consumption of CMR, which contained more $\mathrm{CP}$ and fat compared with CS.

Water disappearance was similar between treatments (Table 4), and was highly correlated with CS intake $(r=0.85 ; n=5,745)$. This is consistent with previous research (Kertz et al., 1984) that indicates a high correlation between water intake and CS intake. Daily water intake (Figure 4 ) was $<2 \mathrm{~L} / \mathrm{d}$ for all calves until d 28. When calves fed CON were weaned, intake of water immediately increased from $<2$ to approximately $4 \mathrm{~L} / \mathrm{d}$ and then increased to the end of the study. The ratio of water intake to total DM was approximately $2 \mathrm{~L} / \mathrm{kg}$ of DM before weaning and $4 \mathrm{~L} / \mathrm{kg}$ of DM after weaning (Figure 5). Ratio of water to DM intake increased dramatically in calves fed CON for the $4 \mathrm{~d}$ following weaning as intake of water increased faster than intake of CS. Intake of water in calves fed VAR and GAM began to increase when amount of CMR offered was reduced from 3.8 to $1.8 \mathrm{~L} / \mathrm{d}$. From d 28 to 31 , mean daily low temperatures increased from approximately 10 to $20^{\circ} \mathrm{C}$ and remained at approximately $20^{\circ} \mathrm{C}$ to the end of the study. Mean daily high temperatures increased from approximately $25^{\circ} \mathrm{C}$ on $\mathrm{d} 28$ to approximately $30^{\circ} \mathrm{C}$ on $\mathrm{d} 32$; thereafter, daily high temperatures were approximately $30^{\circ} \mathrm{C}$ to the end of the study. 


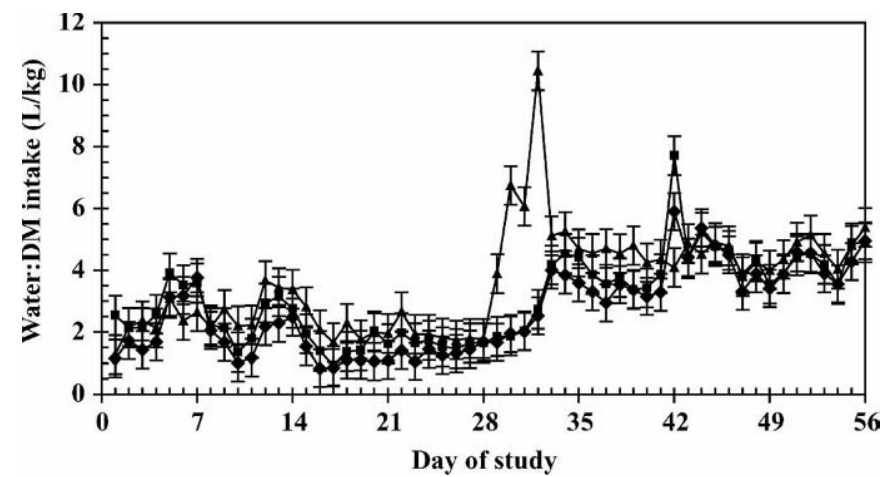

Figure 5. Ratio of water to total DM intake of calves fed calf milk replacer $(\mathrm{CMR})$ at $454 \mathrm{~g} / \mathrm{d}(\boldsymbol{\Delta})$ to $28 \mathrm{~d}$ or 454 to $908 \mathrm{~g} / \mathrm{d}$ of CMR to $42 \mathrm{~d}$ without (ם) or with added dietary supplement $(\bullet)$.

Feed costs were calculated, assuming that CMR used in CON and VAR/GAM treatments cost $\$ 2.09$ and $\$ 1.67 /$ $\mathrm{kg}$, respectively, and CS cost $\$ 0.44 / \mathrm{kg}$. Least squares mean costs of CMR consumed were $\$ 20.99(\mathrm{SE}=2.36)$, $\$ 48.21(\mathrm{SE}=2.16)$, and $\$ 53.42(\mathrm{SE}=2.19)$ for calves fed CON, VAR, and GAM, respectively $(P<0.001)$. Costs of $\mathrm{CS}$ intake were $\$ 25.67(\mathrm{SE}=1.75), \$ 16.75(\mathrm{SE}=$ $1.60)$, and $\$ 17.85$ ( $\mathrm{SE}=1.63)$, respectively, and were higher in calves fed additional CMR $(P<0.001)$. Least squares means of total cost, including feed, labor ( $\$ 10 /$ $\mathrm{hr}$ ), antibiotics ( $\$ 1.56 /$ dose), electrolytes ( $\$ 0.90 /$ dose), value of calf ( $\$ 100 /$ calf), and carcass disposal ( $\$ 10 /$ calf) were higher $(P<0.0001)$ for calves fed variable amount of CMR and were $\$ 83.23$ ( $\mathrm{SE}=3.78$ ), $\$ 128.63$ ( $\mathrm{SE}=$ 3.46), and $\$ 131.38$ ( $\mathrm{SE}=3.51)$ for calves fed CON, VAR, and GAM, respectively. Additionally, feed cost per kilogram of BW gain was higher $(P<0.05)$ for calves fed additional CMR and were $\$ 1.77, \$ 1.92$, and $\$ 2.31$ for calves fed CON, VAR, and GAM, respectively. These costs are lower than those reported by Brown et al. (2005) for calves during the first 8 wk of life due to lower cost assigned to CMR and greater BW gain in calves fed CON in this study.

Concentrations of IGF-I were affected by amount of CMR fed (Table 4) and were consistently higher in calves fed additional CMR. Least squares means of IGFI concentrations on $\mathrm{d} 7,14,28,42$, and 56 (Figure 6) were affected by day and a day $\times$ treatment interaction. Concentrations increased to $28 \mathrm{~d}$ in all calves, then declined to $\mathrm{d} 42$. It is noteworthy that calves fed additional CMR maintained higher concentrations of IGFI on $\mathrm{d} 56$ than calves fed CON, even though both groups of calves had been weaned for at least $2 \mathrm{wk}$. Concentrations of IGF-I were higher in the current study than in some reports (Smith et al., 2002; Brown et al., 2005) but similar to others (Hammon et al., 2002).

Concentrations of $\mathrm{GH}$ were unaffected by treatment (Table 4). Least squares means of GH concentration on



Figure 6. Plasma IGF-1 concentration of calves fed calf milk replacer (CMR) at $454 \mathrm{~g} / \mathrm{d}(\mathbf{\Delta})$ to $28 \mathrm{~d}$ or 454 to $908 \mathrm{~g} / \mathrm{d}$ of CMR to 42 $\mathrm{d}$ without $(\mathbf{\square})$ or with added dietary supplement $(\bullet)$.

d 7, 14, 28, 42, and 56 (Figure 7) generally declined from approximately 4.3 to $3.3 \mathrm{ng} / \mathrm{mL}$ by $56 \mathrm{~d}$ but without effect of treatment. Concentrations of GH were significantly correlated with gain to feed ratio $(\mathrm{r}=-0.17 ; P<$ $0.002)$ and fecal score $(\mathrm{r}=0.14 ; P<0.002)$. Concentrations of GH were higher early in the study when calves were exposed to greater enteric pathogens (contributing to diarrhea) and stress due to shipment (resulting in poor feed efficiency). Others (Hammon and Blum, 1997; Hammon et al., 2002) have reported changes in circulating GH concentrations with increasing age, but little effect of feeding rate on GH concentrations.

Plasma glucose and urea $\mathrm{N}$ concentrations were higher in calves fed additional CMR (Table 4) and both metabolites were affected by a day $\times$ treatment interaction. Weekly least squares means of urea $\mathrm{N}$ (Figure 8) were higher in calves fed additional CMR on d 7, 14, and 28, when calves were still consuming CMR. Plasma urea $\mathrm{N}$ concentration in calves fed additional CMR on d 7 was $5.9 \mathrm{mmol} / \mathrm{L}$, which suggests that a portion of the added CP in the CMR consumed by calves was used

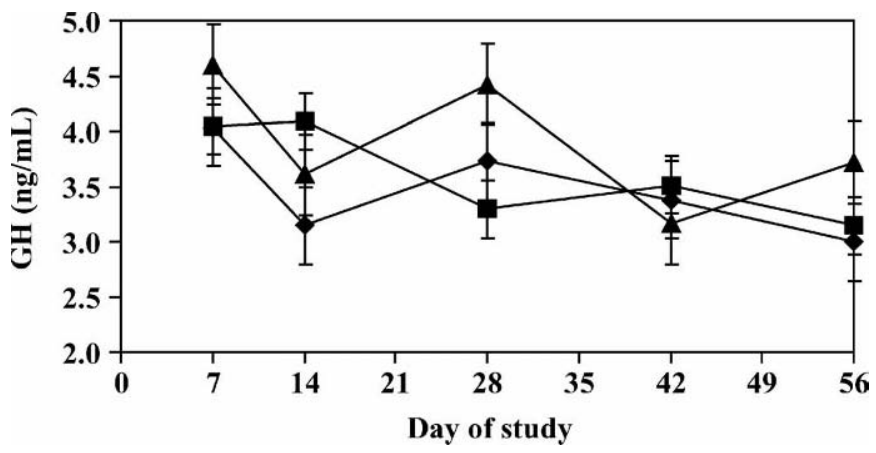

Figure 7. Growth hormone concentration of calves fed calf milk replacer $(\mathrm{CMR})$ at $454 \mathrm{~g} / \mathrm{d}(\boldsymbol{\Delta})$ to $28 \mathrm{~d}$ or 454 to $908 \mathrm{~g} / \mathrm{d}$ of CMR to $42 \mathrm{~d}$ without (ם) or with added dietary supplement $(\bullet)$. 


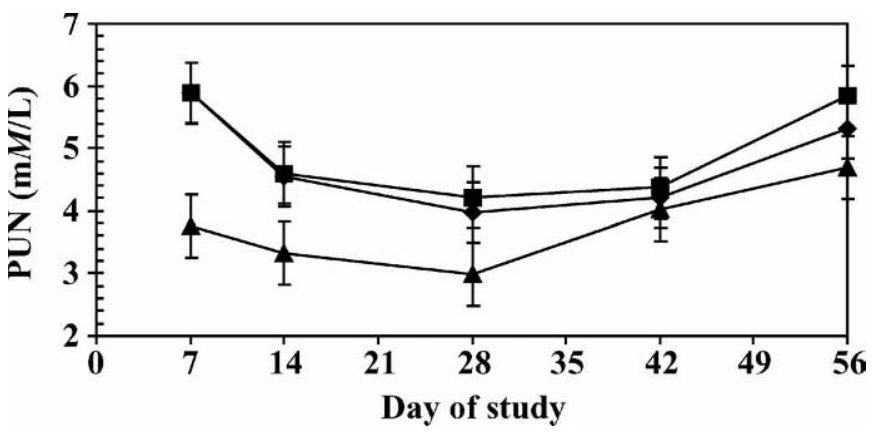

Figure 8. Plasma urea $\mathrm{N}$ concentration of calves fed calf milk replacer (CMR) at $454 \mathrm{~g} / \mathrm{d}(\boldsymbol{\Delta})$ to $28 \mathrm{~d}$ or 454 to $908 \mathrm{~g} / \mathrm{d}$ of CMR to $42 \mathrm{~d}$ without (ם) or with added dietary supplement ( $)$.

for energy with subsequent deamination and increased urea $\mathrm{N}$ concentration. Calves on all treatments also lost BW during the first $7 \mathrm{~d}$ of the study. Others (Smith et al., 2002; Blome et al., 2003) reported lower PUN concentrations in calves fed CMR containing 16 to $30 \%$ $\mathrm{CP}$ at $7 \mathrm{~d}$ after initiation of feeding. However, those data support the observed decline in PUN concentration with increasing age in our study. Increasing PUN concentrations after weaning in both groups was likely due to ruminal fermentation of dietary protein and absorption of ammonia from the rumen.

Weekly least squares means of plasma glucose (Figure 9) generally followed changes in nutrient source. Plasma glucose decreased at $28 \mathrm{~d}$ in calves fed CON treatment and on d 42 in calves fed additional CMR. Thereafter, glucose concentrations were generally constant or increased slightly to d 56 at approximately 3.6 $\mathrm{m} M / \mathrm{L}$.

Least squares means of plasma NEFA and total protein were unaffected by dietary treatment (Table 4). Concentration of NEFA declined from d 7 to 56 (data not shown) and total protein concentration declined to $\mathrm{d} 14$, then gradually increased to $\mathrm{d} 56$ (data not shown).

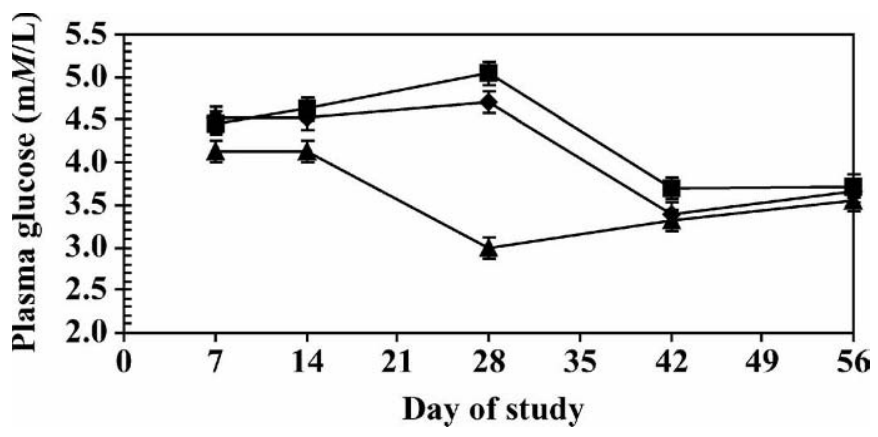

Figure 9. Plasma glucose concentration of calves fed calf milk replacer $(\mathrm{CMR})$ at $454 \mathrm{~g} / \mathrm{d}(\mathbf{\Delta})$ to $28 \mathrm{~d}$ or 454 to $908 \mathrm{~g} / \mathrm{d}$ of $\mathrm{CMR}$ to $42 \mathrm{~d}(\mathbf{\square})$.

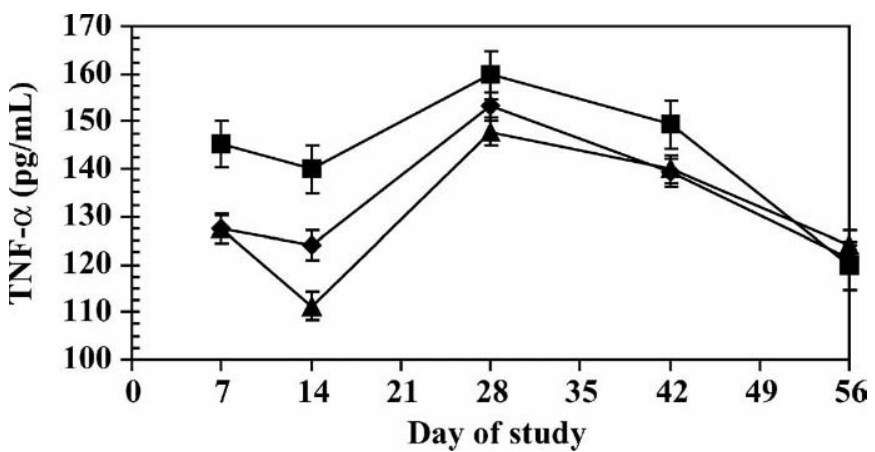

Figure 10. Plasma tumor necrosis factor- $\alpha$ concentration of calves with plasma IgG concentration $>10 \mathrm{~g} / \mathrm{L}(\mathbf{\square}), 5$ to $10 \mathrm{~g} / \mathrm{L}(\diamond)$, and $<5$ $\mathrm{g} / \mathrm{L}(\boldsymbol{\Delta})$.

Least squares means of plasma concentrations of TNF- $\alpha$ were unaffected by dietary treatment (Table 4) and averaged $135 \mathrm{pg} / \mathrm{mL}$. However, passive immunity status and a status $\times$ day interaction were significant $(P<0.004)$. Plasma TNF- $\alpha$ concentration was highest in calves with higher IgG concentrations (adequate group) on $\mathrm{d} 7$ and 14 and was lowest in calves with least plasma IgG concentration (deficient group), particularly on d 14 (Figure 10). Plasma TNF- $\alpha$ concentration of calves with marginal plasma IgG concentration was intermediate between the other groups on $\mathrm{d} 14$. By d 28, differences among groups became less marked and were similar to the end of the study. Generally, plasma TNF- $\alpha$ concentrations were highest on $\mathrm{d} 28$, and then decreased to $\mathrm{d} 56$.

Differences among passive immunity groups may be related to the calf's ability to recognize pathogens and elicit an immune response by stimulation of peripheral macrophages and subsequent production of TNF- $\alpha$. Presumably, calves with least amounts of circulating IgG concentrations were least able to recognize pathogens and, therefore, mounted a weaker immune response (including production of TNF- $\alpha$ ). Moreover, plasma IgG concentration measured in the first week of life is indicative of the degree of colostrum consumption; it is possible that some colostral component other than IgG could be responsible for observed differences in plasma TNF- $\alpha$ concentrations.

Elsasser et al. (1998) reported that plasma TNF- $\alpha$ concentrations in Holstein calves increased during acute phase responses following oral challenge with Sarcocystis cruzi at 4 mo of age. However, other studies have shown variable relationships between pathogenic challenge and plasma TNF- $\alpha$ concentration (Bieniek et al., 1998). In the study of Elsasser et al. (1998), mean plasma TNF- $\alpha$ concentrations ranged from 72 to 109 $\mathrm{pg} / \mathrm{mL}$, which is somewhat lower than mean TNF- $\alpha$ concentrations observed in calves in the present study. 
Calves in our study were exposed to significant stress as evidenced by incidence of morbidity and mortality. Additionally, plasma TNF- $\alpha$ concentrations in response to low-level endotoxin challenge may be affected by protein intake (Kahl et al., 1997) although no effects of milk replacer feeding were observed in this study.

Johnson (1998) stated that decreased food intake in sick or immune-challenged animals is a response orchestrated by cytokines released by activated leukocytes. We hypothesized that neonatal calves exposed to shipping stress followed by exposure to environmental pathogens would be more susceptible to anorexia caused by increase production of cytokines. Although we recorded temporal changes in TNF- $\alpha$ concentrations in blood, these changes were unrelated to dietary treatment. In addition, we estimated anorexia by determining the proportion of calves that refused any part of a CMR feeding and the number of CMR refusals, recognizing that the number of opportunities for calves to refuse CMR was greater in calves fed VAR and GAM, because they were weaned $14 \mathrm{~d}$ later than calves fed CON. There were no differences in proportion of calves refusing CMR or in the number of refusals recorded. Additionally, there were no effects of feeding regimen on concentrations of plasma TNF- $\alpha$, suggesting that feeding method per se had no effect on anorexia or the calf's ability to use ingested nutrients. Increased growth rates were consistent with increased intake of nutrients. However, when conducted under the conditions of this study, feeding additional CMR increased incidence of disease and caused a trend for greater preweaning mortality in calves fed additional CMR. These data suggest that increasing CMR feeding should be done with caution in highly stressed calves.

\section{CONCLUSIONS}

Calves fed additional CMR consumed more CMR, less CS, had greater BW, BW gain, feed efficiency, incidence of diarrhea, and required more veterinary treatments than calves fed CON. Preweaning mortality tended to be greater when calves were fed additional CMR compared with CON. Feed costs and cost per kilogram of $\mathrm{BW}$ gain were also greater. Profiles of plasma metabolites were generally consistent with source and intake of nutrients. Differences in plasma TNF- $\alpha$ concentration associated with plasma IgG concentration suggest that calves with failure of passive transfer are less able to mount immune responses and, therefore, adaptive responses to inflammatory cytokine expression were less well developed. However, dietary treatment did not significantly affect plasma TNF- $\alpha$ concentration.

\section{ACKNOWLEDGMENTS}

The authors acknowledge assistance of L. Ribeiro, A. Tjernagel, and the APC Calf Research Unit staff for calf care, J. Peloquin for laboratory analyses, and H. Tyler for assistance and encouragement in completion of this manuscript.

\section{REFERENCES}

AOAC. 1990. Official Methods of Analysis. Vol. I. 15th ed. Association of Official Analytical Chemists, Arlington, VA.

Balaji, R., K. J. Wright, J. L. Turner, C. M. Hill, S. S. Dritz, B. Fenwick, J. A. Carroll, M. E. Zannelli, L. A. Beausang, and J. E. Minton. 2002. Circulating cortisol, tumor necrosis factor-alpha, interleukin-1 beta, and interferon-gamma in pigs infected with Actinobacillus pleuropneumoniae. J. Anim. Sci. 80:202-207.

Ballard, C. S., H. M. Wolford, C. J. Sniffen, T. Sato, K. Uchida, and Y. Yabuuchi. 2004. The effect of feeding 3 milk replacer regimens preweaning on heifer intake, prepubertal and pubertal growth parameters and reproductive performance. J. Dairy Sci. 87(Suppl. 1):364. (Abstr.)

Bieniek, K., A. Szuster-Ciesielska, T. Kamińska, M. Kondracki, M. Witek, and M. Kandefer-Szerszen. 1998. Tumor necrosis factor and interferon activity in the circulation of calves after repeated injection of low doses of lipopolysaccharide. Vet. Immunol. Immunopathol. 62:297-307.

Blome, R. M., J. K. Drackley, F. K. McKeith, M. F. Hutjens, and G. C. McCoy. 2003. Growth, nutrient utilization, and body composition of dairy calves fed milk replacers containing different amounts of protein. J. Anim. Sci. 81:1641-1655.

Brown, E. G., M. J. Vandehaar, K. M. Daniels, J. S. Liesman, L. T. Chapin, D. H. Heisler, and M. S. Weber Nielsen. 2005. Effects of increasing energy and protein intake on body growth and carcass composition of heifer calves. J. Dairy Sci. 88:585-594.

Bush, R. S., and J. W. G. Nicholson. 1986. The effects of weaning schedule, duration of milk feeding and fishmeal on calf performance. Can. J. Anim. Sci. 66:691-698.

Diaz, M. C., M. E. Van Amburgh, J. M. Smith, J. M. Kelsey, and E. L. Hutten. 2001. Composition of growth of Holstein calves fed milk replacer from birth to 105-kilogram body weight. J. Dairy Sci. 84:830-842.

Elsasser, T. H., T. J. Caperna, and T. S. Rumsey. 1995. Endotoxin administration (EA) decreases plasma insulin-like growth factorI (IGF) and IGF-binding protein (BP) independent of changes in nutritional intake. J. Endocrinol. 144:109-117.

Elsasser, T. H., J. L. Sartin, C. McMahon, G. Romo, R. Fayer, S. Kahl, and B. Blagburn. 1998. Changes in somatotropic axis response and body composition during growth hormone administration in progressive cachectic parasitism. Domest. Anim. Endocrinol. 15:239-255.

Escobar, J., W. G. Van Alstine, D. H. Baker, and R. W. Johnson. 2002. Growth performance and whole-body composition of pigs experimentally infected with Mycoplasma hyopneumoniae. J. Anim. Sci. 80:384-391.

Etzel, L. R., R. E. Strohbehn, and J. K. McVicker. 1997. Development of an automated turbidimetric immunoassay for quantification of bovine serum immunoglobulin G. Am. J. Vet. Res. 58:1201-1205.

Foote, M. R., B. J. Nonnecke, W. R. Waters, M. W. Palmer, M. A. Fowler, B. L. Miller, and D. C. Beitz. 2004. Dietary protein and energy and the adaptive immune response of milk-replacer fed dairy calves. J. Dairy Sci. 87(Suppl. 1):406. (Abstr.)

Hammon, H., and J. W. Blum. 1997. The somatotropic axis in neonatal calves can be modulated by nutrition, growth hormone, and LongR3-IGF-I. Am. J. Physiol. 273:E130-E138.

Hammon, H. M., G. Schiessler, A. Nussbaum, and J. W. Blum. 2002. Feed intake patterns, growth performance, and metabolic and endocrine traits in calves fed unlimited amounts of colostrum and milk by automate, starting in the neonatal period. J. Dairy Sci. 85:3352-3362. 
Hunt, E., Q. Fu, M. U. Armstrong, D. K. Rennix, D. W. Webster, J. A. Galanko, W. Chen, E. M. Weaver, R. A. Argenzio, and J. M. Rhoads. 2002. Oral bovine serum concentrate improves cryptosporidial enteritis in calves. Pediatr. Res. 51:370-376.

Jasper, J., and D. M. Weary. 2002. Effects of ad libitum milk intake on dairy calves. J. Dairy Sci. 85:3054-3058.

Jenkins, N. L., J. L. Turner, S. S. Dritz, S. K. Durham, and J. E. Minton. 2004. Changes in circulating insulin-like growth factorI, insulin-like growth factor binding proteins, and leptin in weaned pigs infected with Salmonella enterica serovar Typhimurium. Domest. Anim. Endocrinol. 26:49-60.

Johnson, R. W. 1998. Immune and endocrine regulation of food intake in sick animals. Domest. Anim. Endocrinol. 15:309-319.

Kahl, S., T. H. Elsasser, and J. Blum. 1997. Nutritional regulation of plasma tumor necrosis factor- $\alpha$ and plasma and urinary nitrite/ nitrate responses to endotoxin in cattle. Proc. Soc. Exp. Biol. Med. 215:370-376.

Kertz, A. F., L. F. Reutzel, and J. H. Mahoney. 1984. Ad libitum water intake by neonatal calves and its relationship to calf starter intake, weight gain, feces score, and season. J. Dairy Sci. 67:2964-2969.

Littell, R. C., P. R. Henry, and C. B. Ammerman. 1998. Statistical analysis of repeated measures data using SAS procedures. J. Anim. Sci. 76:1216-1231.
NAHMS. 1993. Dairy herd management practices focusing on preweaned heifers. USDA: APHIS:VS, Fort Collins, CO.

Nollet, H., H. Laevens, P. Deprez, R. Sanchez, E. Van Driessche, and E. Muylle. 1999. The use of non-immune plasma powder in the prophylaxis of neonatal Escherichia coli diarrhoea in calves. J. Vet. Med. A. 46:185-196.

NRC. 2001. Nutrient Requirements of Dairy Cattle, 7th rev. ed. Natl. Acad. Press, Washington, DC.

Quigley, J. D., III, and M. D. Drew. 2000. Effects of oral antibiotics or IgG on survival, health and growth in dairy calves challenged with Escherichia coli. Food Agric. Immunol. 12:311-318.

Quigley, J. D., III, C. J. Kost, and T. A. Wolfe. 2002. Effects of spraydried animal plasma in milk replacers or additives containing serum and oligosaccharides on growth and health of calves. J. Dairy Sci. 85:413-421.

SAS Institute. 1990. SAS/STAT User's Guide, 4th ed. SAS Inst. Inc., Cary, NC.

Smith, J. M., M. E. Van Amburgh, M. C. Diaz, M. C. Lucy, and D. E. Bauman. 2002. Effect of nutrient intake on the development of the somatotropic axis and its responsiveness to GH in Holstein bull calves. J. Anim. Sci. 80:1528-1537.

Turner, J. L., S. S. Dritz, J. J. Higgins, K. L. Herkelman, and J. E. Minton. 2002. Effects of a Quillaja saponaria extract on growth performance and immune function of weanling pigs challenged with Salmonella typhimurium. J. Anim. Sci. 80:1939-1946. 